\title{
First report of Alternaria alternata causing leaf spot on Salvia involucrata in Italy
}

\author{
Angelo Garibaldi ${ }^{1} \cdot$ Giulia Tabone $^{1} \cdot$ Slavica Matić ${ }^{1} \cdot$ Incoronata Luongo ${ }^{2} \cdot$ Maria Lodovica Gullino $^{1}$
}

Received: 6 March 2020 / Accepted: 16 April 2020 / Published online: 8 May 2020

(C) Società Italiana di Patologia Vegetale (S.I.Pa.V.) 2020

Keywords Ornamental plants $\cdot$ Leaf spots $\cdot$ Gardens

In the summer-autumn 2019 plants of Salvia involucrata (Lamiaceae family) grown in a private garden near Biella (northern Italy), showed light-brown leaf spots that progressively enlarged causing the fall of the leaves. The disease affected $20 \%$ of the plants. From the margins of the necrotic tissues olivaceous fungal colonies were isolated with a frequency of $90 \%$. The fungus grown on PDA produced dark-brown, ovoid or ellipsoid conidia, with 1 to 3 transverse and 0 to 1 longitudinal septa. They measured 8.7 to 36.9 (average 19.1) $\times$ 4.5 to 12.4 (average 8.4) $\mu \mathrm{m}(n=50)$ and some of them showed a light or brown short beak, 1.5 to 5.6 (average 3.6) $\mu \mathrm{m}$. On the basis of these morphological characteristics the fungus was identified as Alternaria sp. (Simmons 2007). From the DNA of the isolate coded 19/47 a PCR was carried out for ITS, $r p b 2$, endoPG and OPA 10-2 region (Woudenberg et al. 2015) (GenBank accession Nos. MN622996; MN615843; MN615842; MN615844, respectively). A BLASTn analysis exhibited $100 \%$ identity with the ex-type CBS 916.96 of Alternaria alternata in ITS, and OPA10-2 (AF347031, KP124632, respectively), and 99\% identity in rpb2, and endoPG regions (KC584375, JQ811978, respectively). Three repeated pathogenicity tests (three plants/test) were carried out on plants of S. involucrata. Leaves were sprayed with a water suspension $(5 \mathrm{ml} /$ plant $)$ at a concentration of $10^{5}$ conidia $/ \mathrm{ml}$. Three plants inoculated with deionized water served as control. The plants, covered with plastic transparent bags for 5 days, were maintained in a greenhouse at $20-25^{\circ} \mathrm{C}$. Leaf spots were observed on inoculated plants and A. alternata was re-isolated with a frequency of $90 \%$ while the controls showed no symptoms. A. alternata was reported on several species of sage (Farr and Rossman 2020). This is the first report of A. alternata on $S$. involucrata in Italy as well as elsewhere.

\section{References}

Farr DF, Rossman AY (2020) Fungal databases, U.S. National Fungus Collections, ARS, USDA. Retrieved March 4, 2020, from https://nt. ars-grin.gov/fungaldatabases/

Simmons EG (2007) Alternaria: an identification manual. CBS Biodiversity Centre, Utrecht, The Netherlands

Woudenberg JHC, Seidl MF, Groenewald JZ, De Vries M, Stielow JB, Thomma BPHJ, Crous PW (2015) Alternaria section Alternaria: species, formae speciales or pathotypes? Stud Mycol 82:1

Publisher's note Springer Nature remains neutral with regard to jurisdictional claims in published maps and institutional affiliations.

Giulia Tabone

giulia.tabone@unito.it

1 Centre of Competence for the Innovation in the Agro-Environmental Sector (AGROINNOVA), University of Torino, Largo Paolo Braccini 2, 10095, Grugliasco, Torino, Italy

2 Disafa, University of Torino, Largo Paolo Braccini 2, 10095, Grugliasco, Torino, Italy 